\title{
List of documents issued by the Conference of European Statisticians (July 1981-June 1982)
}

Copies of the documents listed can be obtained from the Statistical Division of the ECE, Palais des Nations, $\mathrm{CH}-1211$ Geneva 10. Documents are generally available in English, French and Russian.

- Matters arising from the thirty-seventh session of the Economic Commission for Europe (CES/459).

- Producers and users of offical statistics: a review of the situation in the Netherlands (CES/460).

- Ways and methods to adapt statistics to users' needs (CES/460/Add.1).

- Evaluation of the users' needs for statistics (CES/460/Add.2).

- Experience of the Central Statistical Board of Romania in adapting the statistical information system to the requirements of the planned management of the economic and social activity (CES/460/Add.3).

- The users of the ISTAT statistical information service and data bases (CES/460/Add.4).

- Improvement of state statistics in the USSR - towards the fuller satisfaction of users' needs for statistical information (CES/460/Add.5).

- Building a register-based statistical system: preconditions, consequences and perspectives (CES/461).

- Registers and population censuses in Finland (CES/461/Add.1).

- Possibilities and consequences of replacing exhaustive statistical inquiries of data on the population and the housing conditions by the use of information from administrative registers and electronic data banks (CES/461/Add.2).

- Possibilities of replacing population and housing censuses by using administrative registers (CES/461/Add.3).

- Romania's experience in using the agricultural register as an information source in the statistical enquiry' of the population's agricultural holdings (CES/461/Add.4).

- Administrative registers and major censuses: complementarity or substitutability? (CES/461/Add.5).

- Central registers and administrative data as data source in the Norwegian population census (CES/461/Add.6). 
- Statistical activities under the programme of the subsidiary bodies of the Economic Commission for Europe in 1981/82 and programmes of work for 1982/83 (CES/462).

- Statistical activities of international organizations in Europe (CES/463).

- Statistical work of the Commission of the European Communities (CES/463/Add.1).

- The activities of the Council of Europe in the statistical field (CES/463/Add.2).

- Statistical activities of the Organisation for Economic Co-operation and Development (CES/463/Add.3).

- Information on multilateral co-operation among the Member Countries of the Council for Mutual Economic Assistance in the field of statistical methodology in 1981-1982 (CES/463/Add.4).

- Activities in health statistics of the Regional Office for Europe of the World Health Organization (CES/463/Add.5).

- Statistical co-operation between the Nordic countries (CES/463/Add.6).

- Co-operation of the ECE secretariat with other international organizations (CES/463/Add.7).

- Timeliness, cost and quality attributes of statistics (CES/464).

- Planning of future work on statistical methodology (CES/465).

- Topics for substantive discussion at the thirty-first and later plenary sessions (CES/466).

- European Comparison within the International Comparison Project (ICP) framework (CES/467).

- Methodological problems of environment statistics (CES/468).

- Programme of work for 1982/83 - 1986/87 (CES/469).

- Progress report on the activities of the ECE/UNDP Statistical Computing Project in 1981 (CES/470).

- Report on the activity of the Computing Research Centre, Bratislava, in 1981 (CES/471).

- Report on the activity of the International Computer Education and Information Centre in 1981 (CES/472).

- Guide to energy statistics published by the ECE, the OECD and the SOEC (CES/473).

- Future work on statistics of science and technology (CES/474).

- International migration flows among ECE countries, 1976 and 1977 (CES/475).

- Future work on statistics of air quality (CES/476).

- Future work on statistics of engineering industries and automation (CES/477).

- Statistics on the situation of women (CES/478).

- Report of the thirtieth plenary session (ECE/CES/20).

- The systems of national accounts: review of major issues and proposals for future work and short-term changes (CES/WP.22/65).

- Review and development of the United Nations system of national accounts (CES/WP.22/66).

- Review of the treatment of external transactions: draft reconciliation of the classification of the SNA and the IMF balance of payments annual (CES/WP.22/67). 
- Co-operation among CMEA member countries in improving the methodology of the statistical balance of the national economy (CES/WP.22/68).

- Information of the Hungarian system of balances of the national economy (CES/WP.22/69).

- Recent developments in the Polish system of national accounts and balances (CES/WP.22/70).

- Co-ordination of economic statistics with the national accounts and balances (CES/WP.22/71).

- Co-ordination of economic statistics with national accounts and balances in Norway (CES/WP.22/71/Add.1).

- Achieving uniformity of the national balance and economic statistics (CES/WP.22/71/Add.2).

- A survey of national practices in the sources and contents of enterprise statistics in countries with centrally planned economies (CES/WP.22/72).

- Report of the eleventh session held in Geneva, 1-4 June 1982 (CES/WP.22/73).

- Classification of impairments, disabilities and handicaps for use in household surveys (CES/AC.36/20).

- Linking population-based and institution-based data for individuals: procedures and experiences (CES/AC.36/21).

- Social indicators related to the WHO regional strategy for health for all by the year 2000 (CES/AC.36/22).

- Health accounts (CES/AC.36/23).

- Using the international classification of impairments, disabilities and handicaps in houshold surveys: problems and possibilities (CES/AC.36/24).

- Report of the meeting held in Geneva, 15-18 February 1982 (CES/AC.36/25).

- Comparison of retail price indices with and without indirect taxes 1963-1981: a case study of an index which excludes indirect taxes (CES/AC.49/6).

- Adjusting the consumer price index for changes in the rates of indirect taxes and subsidies (CES/AC.49/7).

- Some methodological problems in the computation of a net price index (CES/AC.49/8).

- The Netherlands' price index number of the cost of living, base $1951=100$ (CES/AC.49/9).

- The United Kingdom tax and price index (TPI) (CES/AC.49/10).

- Excluding the effects of changes in import prices from a consumer price index (CES/AC.49/11).

- Calculation of consumer expenditure parities for various national uses (CES/AC.49/12).

- The treatment of owned accommodation in the Canadian consumer price index (CES/AC.49/13).

- Measurement of price movements when the supply of goods and services varies: durable goods and rents (CES/AC.49/14).

- Housing in the Spanish consumer price index (CES/AC.49/15).

- Measuring the cost of shelter for homeowners: theoretical and empirical considerations (CES/AC.49/16). 
- Durable goods, dwellings and credit in consumer price indices (CES/AC.49/ 17).

- Treatment of quality changes (CES/AC.49/18 plus addendum).

- Computation of the effects of changes in import prices in Yugoslavia (CES/AC.49/19).

- Irish constant tax price index (CES/AC.49/20).

- Report of the joint meeting held in Geneva from 5 to 8 October 1981 (CES/AC.49/21).

- Development of social indicators in the field of housing and human settlements (CES/AC.55/2).

- Recent work conducted by international organizations on social indicators in the field of housing and human settlements (CES/AC.55/3).

- Review of the annual bulletin of housing and building statistics for Europe (CES/AC.55/4).

- European programme of current housing statistics (CES/AC.55/5).

- National reports on recent developments in housing sample surveys (CES/AC.55/6 plus addendum).

- Report of the meeting held in Geneva, 15-18 March 1982 (CES/AC.55/7).

- Proposal for a draft standard international classification of water use and quality (CES/AC.56/2).

- Collection of water use statistics from users in the economic sector (CES/AC.56/3).

- From water quality to the ecosystem concept: experience gained from a case study of the stress response environmental statistical system as applied to the Laurentian Lower Great Lakes (CES/AC.56/4).

- Problems of co-ordination and harmonization of the statistics of water use and quality of water required by different organs in Czechoslovakia (CES/ AC.56/5).

- Approaches followed in compiling aggregated water quality information, with particular reference to the design of sampling and laboratory systems (CES/AC.56/6).

- Inventory of the degrees of pollution of surface water in France (CES/AC.56/7).

- Links between water quality standards and collection of water quality statistics - the Hungarian experience (CES/AC.56/8).

- Co-ordinating and harmonizing national data and statistics on water use and water quality (CES/AC.56/9).

- Approaches for collection information on water quality (CES/AC.56/10).

- Methods and information systems for evaluating water resources and needs (CES/AC.56/15).

- Report of meeting held in Geneva, 18-21 January 1982 (CES/AC.56/16).

- Report of the Seminar held in Moscow, 21-25 September 1981 (CES/SEM.14/3).

- The role of, and the interrelationship between the department of statistics and research (D.S.R.) and other organisations concerned with the collection, 
processing and analysis of social, economic administrative and statistical information (CES/SEM.14/R.1).

- "From statistics to data management: the French difficulties" (CES/SEM.14/ R.2).

- Experiences with a new form of statistical dissemination (CES/SEM.14/R.3).

- Interrelationship between national statistical offices and other organizations (CES/SEM.14/R.4).

- The effect of new technology on national information systems (CES/SEM.14/R.5).

- Some technical issues in the regionalization of statistical activities in Canada (CES/SEM.14/R.6).

- Some questions of ensuring statistical information for local authorities using modern methods of information collection and processing in the German Democratic Republic (CES/SEM.14/R.7).

- Regionalization of statistical activities - problems and new technical possibilities (CES/SEM.14/R.8).

- Role of modern methods in regionalization of statistical activities (CES/SEM.14/R.9).

- Some aspects of maintaining and improving statistical qualities in developing a new production model (CES/SEM.14/R.10).

- Co-ordination as an instrument to improve the quality of statistics (CES/SEM.14/R.12).

- Field supervision zones in accordance with the correlated component of the response variance (CES/SEM.14/R.13).

- An anthology of views and comments (CES/SEM.14/R.14).

- Progress report on the implementation of the databank CRONOS-EUROSTAT on EURONET (CES/SEM.14/R.15).

- Experience gained in training of staff in the use of EDP technology (CES/SEM.14/R.16).

- Methods used to obtain a high quality timeliness and reliability of the statistical information (CES/SEM.14/R.17).

- Experience gained in the training of staff in the use of EDP technology for the processing of statistical information (CES/SEM.14/R.18).

- Assisted coding for the 1980 population census (CES/SEM.15/R.1).

- The development of a decentralized data entry system in the Hungarian Central Statistical Office - plans and experience (CES/SEM.15/R.2).

- Statistics Canada experience in on-line data capture (CES/SEM.15/R.3).

- Some methods of data entry in use at the Central Statistical Office (CES/SEM.15/R.4).

- The role of data bases in the dissemination of statistics (CES/SEM.15/R.5).

- The use of displays by statisticians in the State Central Statistical Office (SCSO) of the German Democratic Republic (CES/SEM.15/R.6).

- Terminal interfaces in statistical computing at the United Kingdom Office of Population Censuses and Surveys (CES/SEM.15/R.7).

- CRTP - a system for supporting the interactive dialogue (CES/SEM.15/R.8). 
- The interactive evaluation of data on input-output relations (CES/SEM.15/ R.9).

- Terminal-oriented software for the construction and application of models in macroeconomic statistical analysis and forecasting (CES/SEM.15/R.10).

- User access to a pilot data base (CES/SEM.15/R.11).

- Approach to solution of top data bank of the statistical information system (CES/SEM.15/R.12).

- The metainformation system and the conceptual level of statistical data modelling (CES/SEM.15/R.13).

- The data bank model in the automated statistical information system (CES/SEM.15/R.14).

- More on information modelling at Statistics Canada (CES/SEM.15/R.15).

- Mini-computers used for data entry and processing in the Central Statistical Board of the USSR (CES/SEM.15/R.16).

- Development of survey estimation software compatible with TPL (CES/ SEM.15/R.17).

- Correspondence table between the Standard International Trade Classification of the United Nations: Statistical Standards and Studies No. 32 (sales no: E/R 82 II E 10). 